\title{
Divided attention modulates semantic activation: Evidence from a nonletter-level prime task
}

\author{
Sachio Otsuka AND JUn KaWaguchi \\ Nagoya University, Furocho, Chikusaku, Nagoya, Aichi, Japan
}

\begin{abstract}
Research has recently shown that semantic activation is modulated in proportion to the amount of attention required for letter-level processing of the prime (the attention modulation hypothesis; Smith, Bentin, \& Spalek, 2001). In this study, we examined this hypothesis with an auditory divided-attention task. Participants were asked to decide whether the pitch of a probe tone presented with the prime word was higher or lower than the basic tone presented with the fixation cross. Their target task was lexical decision to the target word. Experiment 1 showed that semantic priming was modulated by the amount of attentional resources. Moreover, in Experiment 2, this modulation was also found in a situation that eliminated the possibility of participants' response strategies. Yet, Experiment 3 showed repetition priming to be unaffected. These results support an amended attention modulation hypothesis in which modulation is not limited to letter-level processing.
\end{abstract}

Priming refers to the idea that the processing of a target is facilitated when it is preceded by a related prime. Meyer and Schvaneveldt (1971) performed the classic demonstration of semantic priming in which participants were asked to judge whether pairs of items were words or nonwords. The words included pairs of related words (e.g., bread and butter) and pairs of unrelated words (e.g., nurse and butter). Participants responded $85 \mathrm{msec}$ faster to the related pairs than to the unrelated pairs. This result was confirmed by a great many additional studies (e.g., Neely, 1977, 1991).

Priming has been explained using the concept of spreading activation (Collins \& Loftus, 1975), in which identification of the prime word activates related words including the target word, thereby making the target easier to judge. Moreover, using a variety of experimental procedures, semantic priming has also been explained by conscious expectancy (Becker, 1980; Neely, 1977), strategic semantic matching (Neely, Keefe, \& Ross, 1989), compound cuing (McKoon \& Ratcliff, 1992), episodic prime retrieval (Bodner \& Masson, 2001), and automatic semantic integration (Chwilla, Hagoort, \& Brown, 1998; Hodgson, 1991).

Although many factors may influence semantic priming, one focus of recent work has been on the way that the prime is processed. In particular, studies have examined the effect that dividing attention by adding a secondary task has on processing of the prime. These studies have shown that semantic priming is not observed when participants direct their attention to the letter level of the prime (e.g., by searching for a particular letter in the prime) rather than to the prime as a lexical or semantic entity. For example, Henik, Friedrich, and Kellogg (1983) investigated the influence of prime task (naming vs. letter search) on target task (lexical decision and word color naming), and they reported the absence of priming on both target tasks when the prime task was letter search. This result suggests that semantic activation is influenced by the level of prime word processing (Besner, Smith, \& MacLeod, 1990; Chiappe, Smith, \& Besner, 1996; Friedrich, Henik, \& Tzelgov, 1991; Henik et al., 1983; Henik, Friedrich, Tzelgov, \& Tramer, 1994; Hoffman \& MacMillan, 1985; Kahneman \& Henik, 1981; Kaye \& Brown, 1985; MaríBeffa, Fuentes, Catena, \& Houghton, 2000; Smith, 1979; Smith, Meiran, \& Besner, 1996, 2000; Smith, Theodor, \& Franklin, 1983; Stolz \& Besner, 1996, 1997, 1998).

Besner et al. (1990) investigated the influence of the letter search task on priming when the prime and target were presented simultaneously. Their task required participants to judge whether two words had letters in common. The reaction times (RTs) for letter search were slow, especially for pairs of related words as opposed to unrelated words. In addition to the explanation of attention required to process the related words and interference generated via letterlevel activation, Besner et al. (1990) postulated an inhibitory mechanism that blocks or attenuates the probability of other lexical units competing at the letter level. According to their proposal, the particular output of a lexical structure can be inhibited, thereby preventing facilitation from a related context and even - under some conditions (e.g., letter search task for the prime) - producing interference. Ordinarily, the activation of related conceptual representations within the semantic system produces top-down activation of the orthographic and letter features of related words that may be the basis for semantic priming following normal reading of related primes. If, however, the prime task re-

S. Otsuka, s050307d@mbox.nagoya-u.ac.jp 
quires letter-level processing, top-down activation of the letters of related words may be a disadvantage for processing of the prime, and therefore must be inhibited.

Henik et al. (1994) explored priming using the letter search task when the stimulus onset asynchrony (SOA) between prime and target was short $(240 \mathrm{msec})$ versus when it was long $(840 \mathrm{msec})$. They employed a delayed dualresponse procedure (Friedrich, 1993) in which participants were required to name the target first and then make their prime response. A typical dual-task procedure in which participants first respond to the prime and next respond to the target cannot provide a stable SOA, but their modification did provide a way to stabilize the SOA between the prime and target. In the prime letter search task, a given letter was replicated above every letter of the prime, and participants judged whether the replicated letter was present in the prime. The target task was lexical decision.

The RT data in Henik et al. (1994) revealed no priming at either SOA following the letter search task. These results were explained by activation blocking - that the spread of semantic activation was blocked between the word level and the semantic level. However, under certain conditions, letter search on the prime did generate semantic priming. In particular, the proportion of related trials in the experiment affected the pattern of semantic priming following letter search. When the proportion of related pairs of prime and target words was $50 \%$, there was no semantic priming with the letter search task, but there was with the naming task. On the other hand, when the proportion of related prime-target words was $80 \%$, they observed semantic priming following both naming and letter search prime tasks. This pattern of the results was observed for both the short $(240 \mathrm{msec})$ and the long $(840 \mathrm{msec})$ SOAs. They suggested that when the prime-target relation was highly salient to the participants, this saliency promoted semantic activation and that, eventually, semantic priming occurred.

Another type of letter-level task-a consonant-vowel task-was introduced by Smith, Bentin, and Spalek (2001). They examined priming on two letter-level prime tasks, again with short (200 msec) and long (1,000 msec) SOAs. They used the letter search task and their new consonant-vowel task as the letter-level prime tasks. The letter search task required participants to determine whether the target letter presented above each letter of the prime was present in the prime, thus requiring participants to examine all letters of the prime. On the other hand, the consonant-vowel task required participants to decide whether the first letter of the prime was a consonant or a vowel, thereby demanding them to attend only to the first letter of the prime. Thus, the attentional resources required at the orthographic level might differ between these two tasks. Their set of prime tasks also included a semanticlevel decision task in which participants decided whether the prime word represented a living or a nonliving object. Participants did lexical decision for the target stimuli.

The results of Smith et al. (2001) showed no semantic priming following any of the prime tasks at the long SOA $(1,000 \mathrm{msec})$. At the short SOA (200 msec), however, semantic priming occurred in the consonant-vowel task and in the living-nonliving decision task, but not in the letter search task. Moreover, the magnitude of priming was less in the consonant-vowel task than in the living-nonliving task. These findings are not adequately accounted for by the concept of inhibition at the letter level (Besner et al., 1990), because there should be no semantic priming on either of the letter-level tasks if the participants inhibit semantic activation when the prime task involves letter-level processing. Inhibition cannot explain the different priming effects in the two letter-level tasks (i.e., a consonantvowel task and a letter search task).

Smith et al. (2001) developed the attention modulation hypothesis to handle this differential priming. First, they assumed that there is a central capacity that has limited resources and that these resources can be allocated to multiple tasks depending on the demands of these tasks (Kahneman, 1973). Consequently, semantic activation is modulated by the amount of attentional resources allocated to the prime. According to their hypothesis, if full attention is deployed to the letter level for orthographic analysis - as is demanded in the letter search task - then insufficient attentional resources remain available for semantic activation of the prime and no semantic priming occurs. In contrast, with a less demanding letter-level task, such as the consonant-vowel task, some attentional resources remain available for semantic activation, allowing priming to occur.

There is, however, another possibility that is the focus of the present research. The findings of Smith et al. (2001) could be due to the similarity between the prime and target tasks induced by the participants' response strategies of prime processing, not to the availability of attentional resources for the prime. In the letter search task, participants had to search every letter in the prime so that they were less likely to actually read the prime. On the other hand, in the consonant-vowel task, it is possible that participants used the strategy of pronouncing the prime and silent reading to facilitate their consonant-vowel decision, although Smith et al. (2001) argued that participants attended to only the first letter of the prime word. If this analysis is correct, then participants may have processed the entire prime in the consonant-vowel task; in other words, the prime word may have been emphasized at the word level. Because the lexical decision task required participants to process wordlevel information about the target, the similarity of the processes between the consonant-vowel task and the lexical decision task may have resulted in response facilitation to the target word following the consonant-vowel task, but not following the letter search task. In experiments exploring the prime task effect, greater semantic priming has been observed when the prime task involves naming or silent reading (Henik et al., 1983; Henik et al., 1994; Smith et al., 2000; Smith et al., 1983). If the similarity of tasks for the prime and target influences lexical decision performance, then the arguments that were made by Smith et al. (2001) for their attention modulation hypothesis are not necessarily supported by their experiments.

In summary, the previous studies have provided insufficient evidence to support the claim that when participants perform a letter-level task on the prime, semantic priming 
does not occur or the magnitude of semantic activation decreases. Thus, the purpose of this article is to examine whether semantic activation of the prime word is modulated or eliminated by attentional resources allocated to it. In our study, to avoid the similarity between the prime and target tasks, we adopted an auditory divided-attention task as the secondary task during prime presentation. This change permitted us to investigate whether Smith et al.'s (2001) attention modulation hypothesis is limited to the letter-level prime task or whether semantic activation of the prime word is modulated by the global amount of attentional resources. The relation between semantic activation of words and an auditory secondary task has already been examined (Becker, 1976; Herdman, 1992; Herdman \& Dobbs, 1989; McCann, Remington, \& Van Selst, 2000). However, Smith et al.'s (2001) attention modulation hypothesis has not been considered in terms of dissociating the contribution of sensory modality.

By using an auditory divided-attention task, we can purely manipulate attentional resources without varying the kind of prime task. In Experiment 1, in order to test the attention modulation hypothesis, we conducted a semantic priming experiment with an auditory dividedattention task that was manipulated between blocks. In Experiment 2, in order to examine the possibility that participants may have employed different response strategies across the divided-attention conditions because they were blocked, and in order to solidify the findings of Experiment 1, we replicated Experiment 1, mixing the dividedattention conditions within blocks. In Experiment 3, we further examined the attention modulation hypothesis using both semantic priming and repetition priming to clarify whether the auditory divided-attention manipulation would affect semantic activation in particular.

\section{EXPERIMENT 1}

In Experiment 1, we used an auditory divided-attention task to examine whether the magnitude of semantic priming was modulated as a function of attentional resources allocated to the prime word. We set up three attention conditions: two divided attention (low and high) and one full attention (in this condition, participants performed only the target task). Also, we employed only the short SOA $(250 \mathrm{msec})$, because attentional modulation was found only at the short SOA in Smith et al. (2001). According to the attention modulation hypothesis, the magnitude of semantic priming in the full-attention condition should be greater than that in either the low or the high dividedattention conditions. Moreover, the magnitude of semantic priming in the low divided-attention condition should be greater than that in the high divided-attention condition. However, if semantic activation of the prime word is unaffected by the manipulation of divided attention, then we should observe no difference in the magnitude of semantic priming across the three attention conditions.

\section{Method}

Participants. Twenty-four Japanese undergraduate students at Nagoya University ( 8 men and 16 women, age range $=18-22$ years old) participated. All were right handed and had reported normal or corrected-to-normal visual acuity and normal color vision. They had no hearing problems. All of them participated in all three dividedattention conditions. They received bonus points toward their introductory psychology course for their participation.

Apparatus and Stimuli. This experiment was controlled by an AV tachistoscope (IWATSU ISEC, IS-7301), with the stimuli presented on a color monitor (Mitsubishi, RDF221H) that was located approximately $80 \mathrm{~cm}$ in front of the participants. The refresh rate of the monitor was $100 \mathrm{~Hz}$; image resolution was $512 \times 512$ pixels. Each letter subtended a visual angle of about $2.1^{\circ}$ vertically and $2.1^{\circ}$ horizontally. All stimuli, as well as the fixation cross, were printed in white on a black background. Auditory stimuli were presented through headphones (Roland, RH-50). Participants' responses were measured using the response unit of the AV tachistoscope, with five buttons arranged horizontally (IS-7211).

Two words were presented sequentially, the first being the prime and the second being the target. A total of 288 stimulus pairs were presented to each participant. From the 144 related prime-target word pairs (e.g., clock-time: とけいーじかん), 144 unrelated prime-target word pairs were formed by randomly rearranging the primes and targets (e.g., cigar-time: たばこーじかん). The prime words were composed of, on average, 3.7 letters, and the target words were composed of, on average, 3.5 letters. All words were written in Japanese kana in Gothic font. The stimuli were counterbalanced so that every target appeared in every condition across participants. Thus, we created six experimental lists of stimulus pairs by crossing the two independent variables (i.e., 4 participants saw the target word "time: じかん” in the related and the full-attention condition, 4 saw this word in the related and the low divided-attention condition, 4 saw this word in the related and the high divided-attention condition, 4 saw this word in the unrelated and the full attention condition, 4 saw this word in the unrelated and the low dividedattention condition, and four saw this word in the unrelated and the high divided-attention condition). Finally, we also created 144 word prime-nonword target pairs, with the nonwords formed by changing a single letter of a real word.

Each list consisted of 72 related prime-target word pairs, 72 unrelated prime-target word pairs, and 144 word prime-nonword target pairs. The pairs in the lists were randomly presented in three blocks across participants. Each block consisted of 24 related prime-target word pairs, 24 unrelated prime-target word pairs, and 48 word prime-nonword target pairs. Following Smith et al. (2001), we set up the proportion of related trials in the experiment as $50 \%$ of the word prime-word target pairs.

An auditory tone was presented simultaneously with the fixation cross and the presentation of the prime. All tone stimuli recreated a piano sound and were produced using a sound generator (Roland, SOUND Canvas SC-88 Pro). All tones were extracted from an equally tempered scale, with notes drawn from three major chords (A, D, and G). The following sets of auditory stimuli were used in the divided-attention task. In Stimulus Set 1, the $440.00-\mathrm{Hz}$ tone presented with the fixation cross was the basic tone; the tones in the low divided-attention condition were 174.61 and $1046.50 \mathrm{~Hz}$, and those in the high divided-attention condition were 349.23 and $523.25 \mathrm{~Hz}$. In Stimulus Set 2, the basic tone was $587.33 \mathrm{~Hz}$; the tones in the low divided-attention condition were 246.94 and $1396.90 \mathrm{~Hz}$, and those in the high divided-attention condition were 493.88 and $698.46 \mathrm{~Hz}$. In Stimulus Set 3, the basic tone was $783.99 \mathrm{~Hz}$; the tones in the low divided-attention condition were 329.63 and $1975.50 \mathrm{~Hz}$, and those in the high divided-attention condition were 659.26 and $987.77 \mathrm{~Hz}$. The sound pressure was approximately $50 \mathrm{~dB}$. The sampling rate was $44.1 \mathrm{~Hz}$, which was approximately $22.6 \mu \mathrm{sec}$.

In advance of this experiment, in order to confirm the manipulation of divided attention, we conducted a preliminary study in which 15 naive participants decided as quickly and as accurately as possible whether the tone from the low or high divided-attention conditions was higher or lower than the basic tone. All tones were presented via the headphones. At the beginning, one of the three basic tones 


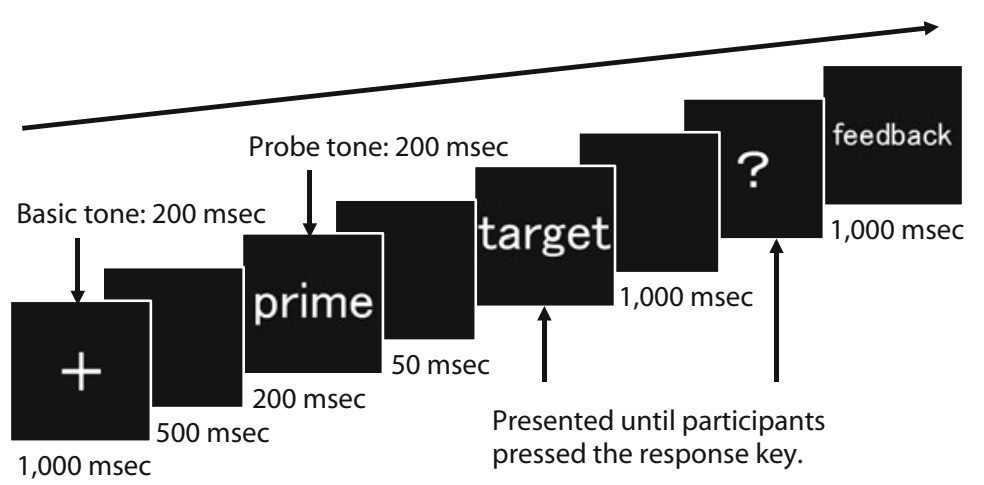

Figure 1. Trial schedules in the low and high divided-attention conditions. In the full-attention condition, the auditory stimuli, the question mark for decision input for the auditory divided-attention task, and the feedback were not presented.

was presented for $200 \mathrm{msec}$, followed by a 500 -msec interval during which no tones were presented. Then, a higher or lower probe tone from the same stimulus set was presented for $200 \mathrm{msec}$. The results of a two-way ANOVA with the factors of divided-attention condition (low vs. high divided attention) and auditory stimulus set (Set 1, 2, or 3 ) showed that mean RTs were longer and percentage error rates were higher in the high divided-attention condition $(641 \mathrm{msec}$ and $13.1 \%$ ) than in the low divided-attention condition (475 $\mathrm{msec}$ and $5.1 \%)$. These differences were both significant $[F(1,14)=15.56$, $M S_{\mathrm{e}}=39,661.97, p<.01$, and $F(1,14)=44.01, M S_{\mathrm{e}}=32.71, p<$ .01 , respectively]. The ANOVA did not reveal reliable effects of stimulus set or of the interaction between divided-attention condition and stimulus set for either RTs or percentage error rates.

Procedure. The experiment was divided into three blocks corresponding to the three divided-attention conditions, with the presentation of divided-attention conditions counterbalanced across participants. Each block consisted of 96 trials, for a total of 288 trials. Before each condition, participants performed 12 practice trials following the delivery of instructions. Half of the 12 practice trials had word prime-target pairs (half of the word targets were related to the prime and the other half were not), and the remaining half had word prime-nonword target pairs. No words or nonwords from the practice phase were used in the experimental trials.

Figure 1 shows an individual trial schedule. Like previous studies (e.g., Henik et al., 1994; Smith et al., 2001), we employed a delayed dual-response procedure to ensure a constant SOA of $250 \mathrm{msec}$. A fixation cross was presented in the center of the computer screen for $1,000 \mathrm{msec}$, with one of the three basic tones simultaneously presented for $200 \mathrm{msec}$ (i.e., the onsets of both stimuli were the same, but a fixation cross was presented for $800 \mathrm{msec}$ longer than the basic tone). After a $500-\mathrm{msec}$ blank screen, the prime word and probe tone were presented for $200 \mathrm{msec}$. Participants decided whether the probe tone was higher or lower than the basic tone, but were instructed not to press the response key at this time. The interstimulus interval between the prime and the target was $50 \mathrm{msec}$; then, the target was presented for lexical decision. Participants were instructed to press the appropriate key with the index finger of the dominant hand if the target was a word or with the middle finger of the dominant hand if it was not a word (in this case, the right two buttons were used), as quickly and accurately as possible. The target was presented until the participant pressed a response key. After a 1,000 -msec blank interval, a question mark was presented in the center of the screen signaling the participant to press either of the appropriate response keys for the auditory task as accurately as possible with the index finger of the nondominant hand (in this case, the left two buttons were used, with the rightmost button always indicating "high" and the left one always indicating "low"). The arrangement of key mapping was counterbalanced across participants (i.e., there were four patterns of key mapping). The question mark disappeared after the participant pressed the key for the auditory task. At the end of each trial, feedback regarding performance on the auditory task was presented for $1,000 \mathrm{msec}$. The intertrial interval was $2,000 \mathrm{msec}$.

Participants performed only the lexical decision task in the fullattention condition. Because auditory stimuli were not presented in the full-attention condition, the question mark for decision input for the auditory divided-attention task and the feedback were not presented. In the full-attention condition, participants pressed the response key for the lexical decision task with one hand.

\section{Results and Discussion}

Mean RTs and error rates were calculated for each of the experimental conditions. We computed mean RTs for correct responses, excluding responses that deviated $2 S D$ s from the individual participants' means. Also, trials involved with an error on the auditory task were excluded from the lexical decision analysis. This trimming procedure was independently performed for each participant and condition. Doing so resulted in excluding 3.1\% of the responses. Priming was calculated by subtracting the means for related words from those for unrelated words.

Lexical decision data. Mean RTs and error rates for the lexical decisions to word targets and nonword targets as a function of each condition are presented in Table 1. A two-way ANOVA was run on the factors of semantic relation (related vs. unrelated) and divided attention (full attention, low divided attention, and high divided attention). The RT data for word targets revealed significant main effects of both semantic relation and divided attention $\left[F(1,23)=23.23, M S_{\mathrm{e}}=1,740.07, p<.01\right.$, and $F(2,46)=57.23, M S_{\mathrm{e}}=15,213.61, p<.01$, respectively] In addition, there was a significant two-way interaction $\left[F(2,46)=9.76, M S_{\mathrm{e}}=1,874.59, p<.01\right]$. A follow-up analysis of simple main effects showed that semantic relation was significant in the full-attention condition and in the low divided-attention condition, but not in the high divided-attention condition $\left[F(1,23)=41.04, M S_{\mathrm{e}}=\right.$ $1,526.41, p<.01 ; F(1,23)=7.49, M S_{\mathrm{e}}=1,863.48, p<$ .05 ; and $F<1$, respectively].

The most interesting question in this experiment was whether the magnitude of semantic priming differed 
among the divided-attention conditions. In fact, the magnitude of semantic priming was significantly greater in the full-attention condition $(72 \mathrm{msec})$ than in the low divided-attention condition (35 msec) $[t(23)=2.13, p<$ $.05]$. There were also significant differences in the magnitude of semantic priming between the full-attention condition and the high divided-attention condition $(-6 \mathrm{msec})$ $[t(23)=4.86, p<.01]$, and between the low and high divided-attention conditions $[t(23)=2.11, p<.05]$.

A similar two-way ANOVA performed on the error rates from word targets revealed no significant effect of semantic relation or divided attention $(F \mathrm{~S}<1)$, and the interaction did not reach significance $(F<1)$.

Thus, on the basis of the RT analyses, these results indicate that the magnitude of semantic priming was modulated as a function of attentional resources allocated to the prime word, even when the prime task was auditory-tone decision. Our findings are consistent with the attention modulation hypothesis (Smith et al., 2001). In the high divided-attention condition, little or no attentional resources would be left for the semantic activation of the prime word, because most resources were allocated to the auditory prime task. On the other hand, in the low dividedattention condition, participants could allocate their resources not only to the auditory divided-attention task, but also to the prime word. In the full-attention condition, the magnitude of semantic priming was the largest among the three conditions, because participants could allocate full attentional resources to the prime word.

An ANOVA on the RTs for nonword targets revealed a significant main effect of divided attention $[F(2,46)=$ 23.21, $\left.M S_{\mathrm{e}}=13,832.12, p<.01\right]$. Tukey's HSD test indicated that RT was quicker in the full-attention condition than in the other conditions, but that there was no significant difference in RT between the low and high dividedattention conditions ( $\mathrm{HSD}=82.34, p<.05)$. A similar ANOVA on the error rates for nonword targets did not show any effect of divided attention $(F<1)$.

Analysis of the RT data for nonword targets showed that the implementation of the prime task delayed the RTs for the target words, but we did not observe a reliable difference between the low and high divided-attention conditions. These results suggest that the attentional resources allocated to the prime task might not necessarily modulate the subsequent decision for nonword targets, and that these critically influence semantic activation of the prime word.
Auditory divided-attention task data. We calculated the mean error rates for the auditory divided-attention task as a function of experimental conditions. A two-way ANOVA run on divided attention (low vs. high) and target type in lexical decision (unrelated word, related word, and nonword) revealed a significant effect of divided attention $\left[F(1,23)=23.01, M S_{\mathrm{e}}=93.83, p<.01\right]$. But the ANOVA did not show any reliable effect of target type or of the interaction between divided attention and target type $\left(F_{\mathrm{S}}<1\right)$. Mean error rates were higher in the high divided-attention condition (12.2\%) than in the low divided-attention condition (4.4\%). This result suggests that, as we expected, the manipulation of the auditory divided-attention task was consistently adequate in this experiment, irrespective of the types of target stimuli in the lexical decision.

\section{EXPERIMENT 2}

The results of Experiment 1 showed that the magnitude of semantic priming was modulated by attentional resources allocated to the prime word. However, because we manipulated the divided-attention conditions across blocks, it is possible that participants attempted to enhance the tone discrimination by focusing only on the tone stimuli and ignoring the prime word when they performed the block of high divided attention. If so, then the absence of priming could be explained by this response strategy. To examine this possibility, we replicated Experiment 1 using a design in which the divided-attention conditions were randomly intermixed within blocks in order to stabilize strategy across the attention conditions.

\section{Method}

Participants. Twenty-four Japanese undergraduate students at Nagoya University ( 5 men and 19 women, age range $=18-50$ years old) who had not participated in Experiment 1 took part in Experiment 2. All were right handed and had reported normal or correctedto-normal visual acuity and normal color vision. They had no hearing problems. They received bonus points toward their introductory psychology course for their participation.

Apparatus and Stimuli. The apparatus, word stimuli, and auditory stimuli were identical to those in Experiment 1, except that we replaced Roland headphones with Sony headphones (MDR-F1).

Procedure. The procedure was identical to that in Experiment 1 except that participants performed 288 trials that were divided into three blocks, but the three attention conditions were randomly intermixed within blocks. Participants performed 24 practice trials

Table 1

Experiment 1: Mean Reaction Times (RTs, in Milliseconds), Percentage of Errors (PEs), and Standard Errors for Lexical Decision to Targets As a Function of Experimental Condition

\begin{tabular}{|c|c|c|c|c|c|c|c|c|c|c|c|c|}
\hline \multirow[b]{3}{*}{ Targets } & \multicolumn{4}{|c|}{ Full Attention } & \multicolumn{4}{|c|}{ Low Divided Attention } & \multicolumn{4}{|c|}{ High Divided Attention } \\
\hline & \multicolumn{2}{|c|}{ RT } & \multicolumn{2}{|c|}{$\mathrm{PE}$} & \multicolumn{2}{|c|}{ RT } & \multicolumn{2}{|c|}{$\mathrm{PE}$} & \multicolumn{2}{|c|}{ RT } & \multicolumn{2}{|c|}{$\mathrm{PE}$} \\
\hline & $M$ & $S E$ & $M$ & $S E$ & $M$ & $S E$ & $M$ & $S E$ & $M$ & $S E$ & $M$ & $S E$ \\
\hline \multicolumn{13}{|l|}{ Word } \\
\hline Unrelated & 627 & 21 & 3.7 & 1.1 & 832 & 19 & 3.7 & 0.7 & 830 & 25 & 3.4 & 0.8 \\
\hline Related prime & 555 & 19 & 3.8 & 1.3 & 797 & 20 & 3.3 & 0.9 & 836 & 28 & 3.3 & 0.7 \\
\hline Nonword & 620 & 20 & 2.6 & 0.5 & 825 & 35 & 2.4 & 0.7 & 815 & 35 & 2.4 & 0.6 \\
\hline Priming effect & $72^{* *}$ & & -.1 & & $35^{*}$ & & 0.4 & & -6 & & 0.1 & \\
\hline
\end{tabular}

Note-Priming was calculated by subtracting the means for the related words from those for the unrelated words. ${ }^{*} p<.05 . \quad{ }^{* *} p<.01$. 
Table 2

Experiment 2: Mean Reaction Times (RTs, in Milliseconds), Percentage of Errors (PEs), and Standard Errors for Lexical Decision to Targets As a Function of Experimental Condition

\begin{tabular}{|c|c|c|c|c|c|c|c|c|c|c|c|c|}
\hline \multirow[b]{3}{*}{ Targets } & \multicolumn{4}{|c|}{ Full Attention } & \multicolumn{4}{|c|}{ Low Divided Attention } & \multicolumn{4}{|c|}{ High Divided Attention } \\
\hline & \multicolumn{2}{|c|}{ RT } & \multicolumn{2}{|c|}{ PE } & \multicolumn{2}{|c|}{ RT } & \multicolumn{2}{|c|}{ PE } & \multicolumn{2}{|c|}{ RT } & \multicolumn{2}{|c|}{ PE } \\
\hline & $M$ & $S E$ & $M$ & $S E$ & $M$ & $S E$ & $M$ & $S E$ & $M$ & $S E$ & $M$ & $S E$ \\
\hline \multicolumn{13}{|l|}{ Word } \\
\hline Unrelated prime & 770 & 34 & 7.1 & 1.3 & 808 & 39 & 4.1 & 1.1 & 802 & 40 & 4.1 & 1.0 \\
\hline Related prime & 709 & 31 & 2.6 & 0.7 & 774 & 36 & 3.2 & 0.9 & 794 & 38 & 3.8 & 1.1 \\
\hline Nonword & 844 & 35 & 5.5 & 1.1 & 868 & 40 & 4.2 & 1.1 & 867 & 34 & 3.7 & 0.9 \\
\hline Priming effect & $61^{* *}$ & & $4.5^{* *}$ & & $34^{* *}$ & & 0.9 & & 8 & & 0.3 & \\
\hline
\end{tabular}

Note-Priming was calculated by subtracting the means for the related words from those for the unrelated words. ${ }^{* *} p<.01$.

before the experiment ( 6 trials were related prime-target pairs that were presented two times in each divided-attention condition, 6 trials were unrelated prime-target pairs, and the remaining 12 had word prime-nonword target pairs that were presented four times in each divided-attention condition).

\section{Results and Discussion}

Mean RTs and error rates were calculated for each experimental condition. We computed mean RTs for correct responses, excluding the responses that deviated $2 S D$ s from the individual participants' means. Also, trials involved with an error on the auditory task were excluded from the lexical decision analysis. This trimming procedure was independently performed for each participant and each condition. Doing so resulted in excluding $4.0 \%$ of the responses. Priming was calculated by subtracting the means for the related words from those for unrelated words.

Lexical decision data. Mean RTs and error rates for the lexical decisions to word targets and nonword targets as a function of each condition are presented in Table 2. A two-way ANOVA was run on semantic relation (related vs. unrelated) and divided-attention condition (full attention, low divided attention, and high divided attention). The RT data for word targets revealed significant main effects of semantic relation and divided attention $[F(1,23)=$ $21.20, M S_{\mathrm{e}}=1,942.03, p<.01$, and $F(2,46)=10.82$, $M S_{\mathrm{e}}=4,502.94, p<.01$, respectively]. In addition, a significant interaction was found between semantic relation and divided attention $\left[F(2,46)=10.61, M S_{\mathrm{e}}=796.26\right.$, $p<.01]$. A follow-up analysis of the simple main effects showed that semantic relation was significant in the fullattention and in the low divided-attention conditions, but not in the high divided-attention condition $[F(1,23)=$ $28.40, M S_{\mathrm{e}}=1,545.41, p<.01 ; F(1,23)=15.81, M S_{\mathrm{e}}=$ 855.40, $p<.01$; and $F<1$, respectively].

The magnitude of semantic priming in the full-attention condition $(61 \mathrm{msec})$ was significantly greater than that in the low divided-attention condition $(34 \mathrm{msec})[t(23)=$ $2.30, p<.05]$. Also, the magnitude of semantic priming in the high divided-attention condition ( $8 \mathrm{msec}$ ) was significantly different from both that in the full-attention condition $[t(23)=4.05, p<.01]$ and that in the low divided-attention condition $[t(23)=2.76, p<.05]$.

A similar two-way ANOVA performed on the error rates from word targets revealed a significant main effect of semantic relation and an interaction between seman- tic relation and divided attention $\left[F(1,23)=7.10, M S_{\mathrm{e}}=\right.$ $18.82, p<.05$, and $F(1,23)=3.76, M S_{\mathrm{e}}=16.37, p<$ .05 , respectively], but no significant effect of divided attention $(F<1)$. A follow-up analysis of the simple main effects showed that semantic relation was significant in the full-attention condition, but not in the low and high divided-attention conditions $\left[F(1,23)=12.10, M S_{\mathrm{e}}=\right.$ 20.27, $p<.01$, and $F \mathrm{~s}<1$, respectively].

Simply summarized, on the basis of the RT analyses, we closely replicated the findings of Experiment 1, even when the three divided-attention conditions were randomly intermixed within blocks - a change that was made to prevent participants from using specific strategies in each divided-attention condition. In other words, because we used the intermixed design in this experiment, it would be very unlikely that participants attempted to enhance the tone discrimination only in the high divided-attention condition by focusing only on the tone stimuli and ignoring the prime word. Thus, we are confident that semantic activation of the prime word is modulated by the attentional resources allocated to the prime, consistent with the attention modulation hypothesis (Smith et al., 2001).

An ANOVA on the RTs and error rates for nonword targets revealed no significant main effects of divided attention $\left[F(2,46)=1.47, M S_{\mathrm{e}}=2,844.23, p=.24\right.$, and $F(2,46)=1.73, M S_{\mathrm{e}}=11.52, p=.19$, respectively].

Auditory divided-attention task data. We calculated the mean error rates for the auditory divided-attention task as a function of experimental conditions. A two-way ANOVA run on divided attention (low vs. high) and target type in lexical decision (unrelated word, related word, and nonword) revealed a significant effect of divided attention $\left[F(1,23)=15.40, M S_{\mathrm{e}}=87.12, p<.01\right]$. But the ANOVA did not show a reliable effect of target type or of the interaction between divided attention and target type $[F(2,46)=$ $1.30, M S_{\mathrm{e}}=30.10, p=.28$, and $F(2,46)=2.19, M S_{\mathrm{e}}=$ $18.23, p=.12$, respectively]. Mean error rates were higher in the high divided-attention condition $(11.8 \%)$ than in the low divided-attention condition $(5.7 \%)$. This result suggests that, as we expected, the manipulation of the auditory divided-attention task was consistently adequate.

\section{EXPERIMENT 3}

If semantic activation of a word is modulated by attention, how is this activation modulated or blocked? Mc- 
Clelland (1987) and McClelland and Rumelhart (1981) proposed an interactive activation model of visual word recognition. This model suggests that visual word recognition involves a process of mutual links between the information received from bottom-up processing, such as the features of words, and the information received from top-down processing, such as knowledge of word and letter identities. This model proposes that activation spreads interactively among three levels during visual word recognition (i.e., letter level, word level, and semantic level). In repetition priming, in which a word is facilitated by its own prior presentation, activation between the letter level and the word level would be important, unlike in semantic priming, which has been shown to be unaffected when the letter search task was used as the prime task in the previous studies (Friedrich et al., 1991; Heil, Rolke, \& Pecchinenda, 2004; Smith \& Besner, 2001), indicating that activation was blocked from the word level to the semantic level.

Smith and Besner (2001) conducted an experiment involving both semantic and repetition priming in which participants performed either a lexical decision or a letter search task on the prime, depending on the color of the target. Their results showed that a semantic context effect was observed in the lexical decision task, indicating the presence of semantic-level activation, but not in the letter search task. In contrast, they observed a robust repetition priming effect for both the lexical decision and letter search tasks. Also, Heil et al. (2004) examined the effect of letter search for a repeated word and found that there was significant repetition priming. Our present results would also imply a block of activation from lower to higher levels. However, it is not clear whether this phenomenon occurs at the stage from the letter level to the word level or from the word level to the semantic level, because we did not manipulate the load of letter-level processing itself in our prime task.

Therefore, in Experiment 3, we replicated Experiment 2 , but added a word repetition condition. If the attentional modulation occurs at the stage between the word and semantic levels, we would expect to see modulation of semantic priming, but no modulation of repetition priming in all of the divided-attention conditions. In contrast, if attentional modulation occurs at the stage between the letter level and the word level, both semantic and repetition priming should be modulated as a function of attentional resources allocated to the prime word.

\section{Method \\ Participants. Thirty-six Japanese graduate and undergraduate students at Nagoya University ( 14 men and 22 women, age range = 18-24 years old) participated in Experiment 3. None had partici- pated in either Experiments 1 or 2 . All were right handed and had reported normal or corrected-to-normal visual acuity and normal color vision. They had no hearing problems. Twenty-five partici- pants received bonus points toward their introductory psychology course for their participation, and the others took part in this experi- ment voluntarily.}

Apparatus and Stimuli. The apparatus was identical to that in Experiment 2.
A total of 432 stimulus pairs were presented to each participant. There were 216 related prime-target word pairs in this experiment (144 pairs were the same as those used in the previous experiments). Unrelated prime-target word pairs were created as in the previous experiments. In the repeated prime-target condition, primes were identical to the subsequent targets (e.g., time-time: じかんー じかん). The prime words were composed of, on average, 3.7 letters, and the target words were composed of, on average, 3.5 letters. We created nine experimental lists of stimulus pairs by crossing the two independent variables so that every target appeared in every condition across participants. There were also 216 word prime-nonword target pairs in Experiment 3 (144 pairs were the same as those used in the previous experiments).

Each list consisted of 72 related prime-target word pairs, 72 repeated prime-target word pairs, 72 unrelated prime-target word pairs, and 216 word prime-nonword target pairs. The pairs in the lists were randomly presented in three blocks across participants. Each block consisted of 24 related prime-target word pairs, 24 repeated prime-target word pairs, 24 unrelated prime-target word pairs, and 72 word prime-nonword target pairs.

Auditory stimuli were identical to those in the previous experiments.

Procedure. The procedure and trial schedule in Experiment 3 were identical to those in Experiment 2, except that participants performed 36 practice trials before the experiment ( 6 trials were related prime-target pairs that were presented two times in each dividedattention condition, 6 trials were repeated prime-target pairs, 6 trials were unrelated prime-target pairs, and the remaining 18 trials had word prime-nonword target pairs that were presented six times in each divided-attention condition) and 432 experimental trials.

\section{Results and Discussion}

Mean RTs and error rates were calculated for each experimental condition. We computed mean RTs for correct responses, excluding the responses that deviated $2 S D \mathrm{~s}$ from the individual participants' means. Also, trials involved with an error on the auditory task were excluded from the lexical decision analysis. This trimming procedure was independently performed for each participant and each condition. Doing so resulted in excluding 3.7\% of the responses. Semantic priming was calculated by subtracting the means for the related words from those for unrelated words. Repetition priming was calculated by subtracting the means for the repeated words from those for unrelated words.

Lexical decision data. Mean RTs and error rates for the lexical decisions to word targets and nonword targets as a function of each condition are presented in Table 3. We separately analyzed related versus unrelated conditions and repetition versus unrelated conditions.

A two-way ANOVA was run on semantic relation (related vs. unrelated) and divided-attention condition (full attention, low divided attention, and high divided attention). The RT data for word targets revealed significant main effects of semantic relation and divided attention $\left[F(1,35)=17.34, M S_{\mathrm{e}}=3,497.67, p<.01\right.$, and $F(2,70)=15.67, M S_{\mathrm{e}}=7,595.81, p<.01$, respectively] In addition, a significant interaction was found between semantic relation and divided attention $[F(2,70)=12.64$, $\left.M S_{\mathrm{e}}=1,761.93, p<.01\right]$. A follow-up analysis of the simple main effects showed that semantic relation was significant in the full-attention and in the low dividedattention conditions, but not in the high divided-attention 
Table 3

Experiment 3: Mean Reaction Times (RTs, in Milliseconds), Percentage of Errors (PEs), and Standard Errors for Lexical Decision to Targets As a Function of Experimental Condition

\begin{tabular}{|c|c|c|c|c|c|c|c|c|c|c|c|c|}
\hline \multirow[b]{3}{*}{ Targets } & \multicolumn{4}{|c|}{ Full Attention } & \multicolumn{4}{|c|}{ Low Divided Attention } & \multicolumn{4}{|c|}{ High Divided Attention } \\
\hline & \multicolumn{2}{|c|}{ RT } & \multicolumn{2}{|c|}{$\mathrm{PE}$} & \multicolumn{2}{|c|}{ RT } & \multicolumn{2}{|c|}{$\mathrm{PE}$} & \multicolumn{2}{|c|}{ RT } & \multicolumn{2}{|c|}{$\mathrm{PE}$} \\
\hline & $M$ & $S E$ & $\bar{M}$ & $\overline{S E}$ & $M$ & $S E$ & $M$ & $S E$ & $M$ & $S E$ & $M$ & $S E$ \\
\hline \multicolumn{13}{|l|}{ Word } \\
\hline Unrelated prime & 724 & 23 & 6.7 & 1.0 & 757 & 27 & 6.3 & 1.1 & 770 & 30 & 6.3 & 1.3 \\
\hline Related prime & 658 & 18 & 2.9 & 0.6 & 719 & 23 & 3.0 & 0.8 & 773 & 31 & 2.6 & 0.7 \\
\hline Repetition prime & 571 & 26 & 2.9 & 0.6 & 632 & 36 & 2.8 & 0.6 & 649 & 31 & 4.0 & 1.1 \\
\hline Nonword & 806 & 23 & 7.6 & 1.8 & 823 & 29 & 4.7 & 1.0 & 861 & 32 & 10.3 & 1.4 \\
\hline Semantic priming & $66^{* *}$ & & 3.8 & & $38^{* *}$ & & 3.3 & & -3 & & 3.7 & \\
\hline Repetition priming & $153^{* *}$ & & 3.8 & & $125^{* *}$ & & 3.5 & & $121^{* *}$ & & 2.3 & \\
\hline
\end{tabular}

Note-Semantic priming was calculated by subtracting the means for the related words from those for the unrelated words. Repetition priming was calculated by subtracting the means for the repetition words from those for the unrelated words. ${ }^{* *} p<.01$.

condition $\left[F(1,35)=41.56, M S_{\mathrm{e}}=1,884.51, p<.01\right.$; $F(1,35)=11.13, M S_{\mathrm{e}}=2,390.49, p<.01 ;$ and $F<1$, respectively].

The magnitude of semantic priming in the full-attention condition $(66 \mathrm{msec})$ was significantly greater than that in the low divided-attention condition $(38 \mathrm{msec})[t(35)=$ $2.42, p<.05]$. Also, the magnitude of semantic priming in the high divided-attention condition $(-3 \mathrm{msec})$ was significantly less than that in both the full-attention condition $[t(35)=4.76, p<.01]$ and the low divided-attention condition $[t(35)=2.72, p<.05]$, which indicated that the magnitude of semantic priming was modulated by the attentional resources allocated to the prime word, entirely consistent with the results of previous experiments.

A similar two-way ANOVA performed on the error rates from word targets revealed a significant main effect of semantic relation $\left[F(1,35)=39.30, M S_{\mathrm{e}}=17.77, p<.01\right]$, but no significant effect of divided attention and interaction between semantic relation and divided attention $\left(F_{\mathrm{S}}<1\right)$.

Next, we conducted a two-way ANOVA run on the repetition (repetition vs. unrelated) and divided-attention condition (full attention, low divided attention, and high divided attention). The RT data for word targets revealed significant main effects of repetition and divided attention $\left[F(1,35)=158.68, M S_{\mathrm{e}}=6,007.23, p<.01\right.$, and $F(2,70)=8.55, M S_{\mathrm{e}}=8,705.81, p<.01$, respectively], but no interaction between repetition and divided attention $(F<1)$. RT for repetition words $(617 \mathrm{msec})$ was quicker than that for unrelated words $(750 \mathrm{msec})$. Tukey's HSD test indicated that RT in the full-attention condition (648 msec) was quickest, but that there was no significant difference between RT in the low (694 msec) and high (709 $\mathrm{msec})$ divided-attention conditions (HSD = 37.31, $p<.05)$. A similar two-way ANOVA performed on the error rates from word targets revealed a significant main effect of repetition $\left[F(1,35)=22.93, M S_{\mathrm{e}}=24.44, p<\right.$ $.01]$, but no significant effects of divided attention or of the interaction between repetition and divided attention $(F \mathrm{~S}<1)$. In summary, on the basis of the RT data, we observed robust repetition priming effects in all of the divided-attention conditions, and no effect of auditory divided-attention manipulation on the magnitude of repetition priming. This result suggests that auditory divided attention affects the processing from the word level to the semantic level and that semantic activation requires attentional resources.

An ANOVA on the RTs and error rates for nonword targets revealed significant main effects of divided attention $\left[F(2,70)=9.68, M S_{\mathrm{e}}=2,919.08, p<.01\right.$, and $F(2,70)=$ 5.44, $M S_{\mathrm{e}}=50.74, p<.01$, respectively]. Tukey's HSD test indicated that RT was slower in the high dividedattention condition than in the other conditions, but that there was no significant difference in RT between the fullattention and low divided-attention conditions (HSD = 30.56, $p<.05$ ). Tukey's HSD test for error rates showed only a significant difference between the low and high divided-attention conditions $(\mathrm{HSD}=4.03, p<.05)$.

Auditory divided-attention task data. We calculated the mean error rates for the auditory divided-attention task as a function of experimental conditions. A two-way ANOVA run on divided attention (low vs. high) and target type in lexical decision (unrelated word, related word, repetition word, and nonword) revealed a significant effect of divided attention $\left[F(1,35)=65.75, M S_{\mathrm{e}}=167.17, p<\right.$ $.01]$. But the ANOVA did not show a reliable effect of target type or of the interaction between divided attention and target type $\left[F(3,105)=1.15, M S_{\mathrm{e}}=50.76, p=.33\right.$, and $F<1$, respectively]. Mean error rates were higher in the high divided-attention condition $(20.9 \%)$ than in the low divided-attention condition $(8.6 \%)$. This result suggests that, as we expected, the manipulation of the auditory divided-attention task was consistently adequate.

\section{GENERAL DISCUSSION}

The attention modulation hypothesis (Smith et al., 2001) suggests that the extent of semantic activation depends on the amount of attentional resources allocated to the prime. However, Smith et al.'s (2001) results might be explained alternatively by the similarity between the consonant-vowel task and the lexical decision task induced by the participants' response strategies for prime processing. In this study, to remove this similarity between the prime task and the target task and thereby test the attention modulation hypothesis, we employed an auditory divided-attention task in presenting the prime. 
The results of Experiment 1 are consistent with Smith et al.'s (2001) attention modulation hypothesis. In the fullattention condition, a typical semantic priming effect was observed. More important, the magnitude of priming in the full-attention condition was the largest among the three conditions, indicating that participants could allocate full attentional resources to the prime word and that the magnitude of semantic activation was sufficient to produce significant semantic priming. In the low divided-attention condition, we also observed significant priming, but its magnitude was smaller than that in the full-attention condition and larger than that in the high divided-attention condition. In the divided-attention conditions, attentional resources were allocated not only to the prime word but also to the auditory prime task, resulting in progressively reduced semantic priming as the competing demands for resources increased. In the high divided-attention condition, most attentional resources were absorbed by the auditory prime task, leaving little resources for the semantic activation of the prime word.

In Experiment 2, we switched from presenting the divided-attention conditions in blocks to presenting them randomly, and we replicated the results of Experiment 1. Because of this manipulation in Experiment 2, we were able to discard another account for the results of Experiment 1-that in the high divided-attention condition only, participants intended to optimize their tone discrimination by focusing their attention only on the tone stimuli and ignoring the prime word. This clearly was not the case, because the priming pattern did not change. In Experiment 3, repetition priming, for which activation between the letter level and the word level would be important, was not affected by the auditory divided-attention manipulation, whereas semantic priming continued to be affected.

In summary, these results suggest that semantic activation is critically modulated by the amount of attentional resources allocated to the prime word, and that auditory divided attention affects the processing from the word level to the semantic level, consistent with numerous studies of visual word recognition (e.g., Besner, Stolz, \& Boutilier, 1997; Chiappe et al., 1996; Smith \& Besner, 2001; Stolz $\&$ Besner, 1996). In addition, the difference in pattern between semantic priming and repetition priming permits us to reject other explanations for our results, such as the idea that the high divided-attention condition caused spreading activation to decay more rapidly than did the other conditions or that tone decision delayed target responding so that spreading activation from a fully activated prime word decayed prior to target responding.

Prior research has been interpreted to indicate that when attention is directed to the letter level of the prime word, priming is interrupted or modulated (Besner et al., 1990; Chiappe et al., 1996; Friedrich et al., 1991; Henik et al., 1983; Henik et al., 1994; Hoffman \& MacMillan, 1985; Kahneman \& Henik, 1981; Kaye \& Brown, 1985; MaríBeffa et al., 2000; Smith, 1979; Smith et al., 2001; Smith \& Besner, 2001; Smith et al., 1996, 2000; Smith et al., 1983; Stolz \& Besner, 1996, 1997, 1998). An important contribution of our study is the suggestion that the influ- ence of the amount of attentional resources used for the prime task is not limited to processing at the letter level: It must influence the processing of low-level features of words, thereby affecting the magnitude of semantic activation. Thus, the attention modulation hypothesis needs to be amended to include attentional modulation that is not limited to letter-level processing.

If semantic processing of the prime is modulated by the availability of attentional resources, as was found in this study, this may contradict the suggestion that fastacting semantic activation is automatic and unavoidable (see, e.g., Neely, 1977; Neely \& Kahan, 2001). The critical postulation for the hypothesis of automaticity in visual word recognition is that the mere presentation of a word is enough to activate its representation (Posner \& Carr, 1992). In addition, automaticity implies that the word processing (1) is not interfered with by other tasks, (2) is not influenced by intention (strategies, expectations, or plans), and (3) proceeds without conscious awareness (Neumann, 1984). However, as with previous studies exploring prime task effects (Besner et al., 1990; Chiappe et al., 1996; Friedrich et al., 1991; Henik et al., 1983; Henik et al., 1994; Hoffman \& MacMillan, 1985; Kahneman \& Henik, 1981; Kaye \& Brown, 1985; Marí-Beffa et al., 2000; Smith, 1979; Smith et al., 2001; Smith \& Besner, 2001; Smith et al., 1996, 2000; Smith et al., 1983; Stolz \& Besner, 1996, 1997, 1998), we found that processing in the auditory divided-attention task blocked or attenuated fast-acting semantic activation, which conflicts with the claim that semantic activation occurs automatically.

Note, however, that we cannot conclusively determine whether the absence of semantic priming in the high divided-attention condition of our experiments and in the letter search studies (e.g., Henik et al., 1994; Smith et al., 2001) reflects the nonautomaticity of semantic activation. In a recent event-related potential study, the N400 waveform, which is influenced by the strength of semantic association, was observed when participants performed a letter search task on the prime, despite the lack of semantic priming effect in the behavioral measure (Heil et al., 2004). Nevertheless, it is not clear that the N400 pattern observed in their study reflects fast-acting semantic activation, because the SOA in their experiment was approximately 2 sec long.

Kahan, Sellinger, and Broman-Fulks (2006) suggested that the elimination of priming by letter search on the prime reflects the blockage of a retrospective process akin to involuntary aware memory (see, e.g., Kinoshita, 2001; Mace, 2003a, 2003b) instead of the blockage of spreading activation. They base this idea on the fact that the SOA between the prime and target is long in letter search experiments in comparison with typical semantic priming experiments (e.g., Neely, 1991). Indeed, studies of the letter search task have used a long prime-target SOA because participants were asked first to search for a common letter within the prime and then to make a lexical decision for the target word. However, like Smith et al. (2001), we used a short SOA with a delayed dual-response procedure (Friedrich, 1993) in which participants withheld the prime response until after the target response had been made. 
Thus, the attenuation and elimination of semantic priming that were observed by Smith et al. (2001) and in our study cannot adequately be explained by the blockage of a retrospective process of the sort that was suggested by Kahan et al. (2006).

In order to compare semantic priming using an immediate and a delayed prime response at a long SOA, Smith et al. (2001) conducted an additional experiment (see the General Discussion in Smith et al., 2001). In their experiment, although the lexical decisions for the target were significantly slower and were associated with more errors when the response to the prime was delayed until after the target response had been made, neither the magnitude nor the pattern of semantic priming was affected by the response delay. This result suggested that the requirement of keeping information about the prime in memory imposed a cognitive load that was revealed as slower target processing, but that it did not affect semantic priming.

Pashler (1994, 1998) has suggested that maintaining a memory load might make people perform other tasks more slowly, because rehearsal prevented them from optimally preparing for the other task. Also, Lavie and her colleagues showed that high memory load increased distractor interference (see, e.g., Lavie, Hirst, de Fockert, \& Viding, 2004). In our study, we did not directly manipulate memory load, and participants had to maintain the tone decision both in the low divided-attention condition and in the high divided-attention condition, so that the memory load was the same in the two conditions. In addition, in a typical priming paradigm, the prime word should not be an ignored stimulus. Because of these features, it is difficult to discuss our results in terms of cognitive load. Instead, our results may be discussed with reference to perceptual load (see Lavie \& Fox, 2000). Namely, it is possible that participants passively allocated their attentional resources to both the tone stimuli and the prime. In this way, a different magnitude of semantic priming was observed between the low and the high divided-attention conditions despite participants having equal memory loads under the two conditions (i.e., participants maintained a single response for the auditory divided-attention task in memory while performing the lexical decision task in both dividedattention conditions).

Finally, our results also indicate that there is a crossmodal influence between an auditory decision and visual word recognition. Mulligan (2003) conducted an experiment on perceptual implicit memory with an auditory attention task. He found that a standard cross-modal manipulation did not eliminate priming in perceptual identification, but when words and distractors were presented synchronously, cross-modal and intramodal divided attention reduced priming. It may be difficult to directly compare our results using an auditory divided-attention task with those of Mulligan, because the procedure of our experiment employed short-duration semantic priming, whereas that used in Mulligan's study employed a standard memory task. On the other hand, a cross-modal interaction between the visual and auditory modalities has also been observed at the early stage of perceptual organization, including emotions (Vroomen \& de Gelder, 2000; Vroomen, Driver, \& de Gelder, 2001). Although it remains an issue of contention whether a cross-modal interaction between the visual and auditory modalities is a mandatory process in the early stage of visual processing, it is quite interesting for researchers studying cross-modal effects that our results show that visual word recognition is influenced by a concurrent auditory divided-attention task in the context of a typical priming paradigm.

In conclusion, we have presented additional and critical evidence for the attention modulation hypothesis that fastacting semantic activation is modulated by the amount of attentional resources allocated to the prime (Smith et al., 2001). Moreover, we argue that the attention modulation hypothesis must be amended to include attentional modulation that is not limited to letter-level processing. Semantic activation of a word is influenced by a dividedattention task, and it does not appear to be necessarily automatic. However, semantic activation may still be "automatic," because participants cannot intentionally control the attention that is allocated to semantic activation and the prime task, suggesting that there may be an "unintentional control" process to visual word recognition.

\section{AUTHOR NOTE}

We thank Sally Andrews, Robin K. Morris, Jennifer A. Stolz, Colin M. MacLeod, and an anonymous reviewer for their insightful comments on an earlier draft of the manuscript. Correspondence concerning this article should be addressed to S. Otsuka or J. Kawaguchi, Department of Psychology, Graduate School of Environmental Studies, Nagoya University, Furocho, Chikusaku, Nagoya 464-8601 Japan (e-mail: s050307d@) mbox.nagoya-u.ac.jp, kawaguchij@cc.nagoya-u.ac.jp).

\section{REFERENCES}

BECKER, C. A. (1976). Allocation of attention during visual word recognition. Journal of Experimental Psychology: Human Perception \& Performance, 2, 556-566.

BECKER, C. A. (1980). Semantic context effects in visual word recognition: An analysis of semantic strategies. Memory \& Cognition, 8 , 493-512.

Besner, D., Smith, M. C., \& MacLeod, C. M. (1990). Visual word recognition: A dissociation of lexical and semantic processing. Journal of Experimental Psychology: Learning, Memory, \& Cognition, 16, 862-869.

Besner, D., Stolz, J. A., \& Boutilier, C. (1997). The Stroop effect and the myth of automaticity. Psychonomic Bulletin \& Review, 4, 221-225.

Bodner, G. E., \& Masson, M. E. J. (2001). Prime validity affects masked repetition priming: Evidence for an episodic resource account of priming. Journal of Memory \& Language, 45, 616-647.

Chiappe, P. R., Smith, M. C., \& Besner, D. (1996). Semantic priming in visual word recognition: Activation blocking and domains of processing. Psychonomic Bulletin \& Review, 3, 249-253.

Chwilla, D. J., Hagoort, P., \& Brown, C. M. (1998). The mechanism underlying backward priming in a lexical decision task: Spreading activation versus semantic matching. Quarterly Journal of Experimental Psychology, 51A, 531-560.

Collins, A. M., \& LofTus, E. F. (1975). A spreading-activation theory of semantic processing. Psychological Review, 82, 407-428.

Friedrich, F. J. (1993, November). Prime task effects on naming RTs. Paper presented at the 34th Annual Meeting of the Psychonomic Society, Washington, DC.

Friedrich, F. J., Henik, A., \& Tzelgov, J. (1991). Automatic processes in lexical access and spreading activation. Journal of Experimental Psychology: Human Perception \& Performance, 17, 792-806. 
Heil, M., Rolke, B., \& Pecchinenda, A. (2004). Automatic semantic activation is no myth: Semantic context effects on the N400 in the letter-search task in the absence of response time effects. Psychological Science, 15, 852-857.

Henik, A., Friedrich, F. J., \& Kellogg, W. A. (1983). The dependence of semantic relatedness effects upon prime processing. Memory \& Cognition, 11, 366-373.

Henik, A., Friedrich, F. J., Tzelgov, J., \& Tramer, S. (1994). Capacity demands of automatic processes in semantic priming. Memory \& Cognition, 22, 157-168.

Herdman, C. M. (1992). Attentional resource demands of visual word recognition in naming and lexical decisions. Journal of Experimental Psychology: Human Perception \& Performance, 18, 460-470.

Herdman, C. M., \& Dobbs, A. R. (1989). Attentional demands of visual word recognition. Journal of Experimental Psychology: Human Perception \& Performance, 15, 124-132.

Hodgson, J. M. (1991). Informational constraints on pre-lexical priming. Language \& Cognitive Processes, 6, 169-205.

Hoffman, J. E., \& MacMillan, F. W. (1985). Is semantic priming automatic? In M. I. Posner \& O. S. M. Marin (Eds.), Attention and performance XI (pp. 585-599). Hillsdale, NJ: Erlbaum.

Kahan, T. A., Sellinger, J. J., \& Broman-Fulks, J. J. (2006). Associative and phonological priming effects after letter search on the prime. American Journal of Psychology, 119, 239-254.

Kahneman, D. (1973). Attention and effort. Englewood Cliffs, NJ: Prentice Hall.

Kahneman, D., \& HeniK, A. (1981). Perceptual organization and attention. In M. Kubovy \& J. R. Pomerantz (Eds.), Perceptual organization (pp. 181-211). Hillsdale, NJ: Erlbaum.

Kaye, D. B., \& Brown, S. W. (1985). Levels and speed of processing effects on word analysis. Memory \& Cognition, 13, 425-434.

Kinoshita, S. (2001). The role of involuntary aware memory in the implicit stem and fragment completion tasks: A selective review. Psychonomic Bulletin \& Review, 8, 58-69.

Lavie, N., \& Fox, E. (2000). The role of perceptual load in negative priming. Journal of Experimental Psychology: Human Perception \& Performance, 26, 1038-1052.

Lavie, N., Hirst, A., De Fockert, J. W., \& Viding, E. (2004). Load theory of selective attention and cognitive control. Journal of Experimental Psychology: General, 133, 339-354.

MACE, J. H. (2003a). Involuntary aware memory enhances priming on a conceptual implicit memory task. American Journal of Psychology, 116, 281-290.

Mace, J. H. (2003b). Study-test awareness can enhance priming on an implicit memory task: Evidence from a word completion task. American Journal of Psychology, 116, 257-279.

Marí-Beffa, P., Fuentes, L. J., Catena, A., \& Houghton, G. (2000). Semantic priming in the prime task effect: Evidence of automatic semantic processing of distractors. Memory \& Cognition, 28 635-647.

McCann, R. S., Remington, R. W., \& Van Selst, M. (2000). A dualtask investigation of automaticity in visual word processing. Journal of Experimental Psychology: Human Perception \& Performance, 26, $1352-1370$.

McClelland, J. L. (1987). The case for interactionism in language processing. In M. Coltheart (Ed.), Attention and performance XII: The psychology of reading (pp. 3-36). Hillsdale, NJ: Erlbaum.

McClelland, J. L., \& Rumelhart, D. E. (1981). An interactive activation model of context effects in letter perception: Part 1. An account of basic findings. Psychological Review, 88, 375-407.

McKoon, G., \& Ratcliff, R. (1992). Spreading activation versus compound cue accounts of priming: Mediated priming revisited. Journal of Experimental Psychology: Learning, Memory, \& Cognition, 18 1155-1172.

Meyer, D. E., \& Schvaneveldt, R. W. (1971). Facilitation in recognizing pairs of words: Evidence of a dependence between retrieval operations. Journal of Experimental Psychology, 90, 227-234.

Mulligan, N. W. (2003). Effects of cross-modal and intramodal division of attention on perceptual implicit memory. Journal of Experimental Psychology: Learning, Memory, \& Cognition, 29, 262-276.
NeEly, J. H. (1977). Semantic priming and retrieval from lexical memory: Roles of inhibitionless spreading activation and limitedcapacity attention. Journal of Experimental Psychology: General, 106, 226-254.

NeELy, J. H. (1991). Semantic priming effects in visual word recognition: A selective review of current findings and theories. In D. Besner \& G. W. Humphreys (Eds.), Basic processes in reading: Visual word recognition (pp. 264-336). Hillsdale, NJ: Erlbaum.

NeEly, J. H., \& Kahan, T. A. (2001). Is semantic activation automatic? A critical re-evaluation. In H. L. Roediger III, J. S. Nairne, I. Neath, \& A. M. Surprenant (Eds.), The nature of remembering: Essays in honor of Robert G. Crowder (pp. 69-93). Washington, DC: American Psychological Association.

Neely, J. H., Keefe, D. E., \& Ross, K. L. (1989). Semantic priming in the lexical decision task: Roles of prospective prime-generated expectancies and retrospective semantic matching. Journal of Experimental Psychology: Learning, Memory, \& Cognition, 15, 1003-1019.

NeumanN, O. (1984). Automatic processing: A review of recent findings and a plea for an old theory. In W. Printz \& A. Sanders (Eds.), Cognition and motor processes (pp. 255-293). Berlin: Springer.

Pashler, H. [E.] (1994). Dual-task interference in simple tasks: Data and theory. Psychological Bulletin, 116, 220-244.

PAshler, H. E. (1998). The psychology of attention. Cambridge, MA: MIT Press.

Posner, M. I., \& CARR, T. H. (1992). Lexical access and the brain: Anatomical constraints on cognitive models of word recognition. American Journal of Psychology, 105, 1-26.

Smith, M. C. (1979). Contextual facilitation in a letter search task depends on how the prime is processed. Journal of Experimental Psychology: Human Perception \& Performance, 5, 239-251.

Smith, M. C., Bentin, S., \& Spalek, T. M. (2001). Attention constraints of semantic activation during visual word recognition. Journal of Experimental Psychology: Learning, Memory, \& Cognition, 27, 1289-1298.

Smith, M. C., \& Besner, D. (2001). Modulating semantic feedback in visual word recognition. Psychonomic Bulletin \& Review, 8, 111-117.

Smith, M. C., Meiran, N., \& Besner, D. (1996). When is a direct test of memory more sensitive than an indirect test? Canadian Journal of Experimental Psychology, 50, 139-148.

Smith, M. C., Meiran, N., \& Besner, D. (2000). On the interaction between linguistic and pictorial systems in the absence of semantic mediation: Evidence from a priming task. Memory \& Cognition, 28, 204-213.

Smith, M. C., Theodor, L., \& Franklin, P. E. (1983). The relationship between contextual facilitation and depth of processing. Journal of Experimental Psychology: Learning, Memory, \& Cognition, 9, 697-712.

Stolz, J. A., \& Besner, D. (1996). Role of set in visual word recognition: Activation and activation blocking as nonautomatic processes. Journal of Experimental Psychology: Human Perception \& Performance, 22, 1166-1177.

Stolz, J. A., \& Besner, D. (1997). Visual word recognition: Effort after meaning but not (necessarily) meaning after effort. Journal of Experimental Psychology: Human Perception \& Performance, 23, 1314-1322.

Stolz, J. A., \& Besner, D. (1998). Levels of representation in visual word recognition: A dissociation between morphological and semantic processing. Journal of Experimental Psychology: Human Perception \& Performance, 24, 1642-1655.

VRoomen, J., \& DE Gelder, B. (2000). Sound enhances visual perception: Cross-modal effects of auditory organization on vision. Journal of Experimental Psychology: Human Perception \& Performance, 26, 1583-1590.

Vroomen, J., Driver, J., \& DE Gelder, B. (2001). Is cross-modal integration of emotional expressions independent of attentional resources? Cognitive, Affective, \& Behavioral Neuroscience, 1, 382-387.

(Manuscript received April 18, 2006; revision accepted for publication March 12, 2007. ) 